Richard L. Knill MD FRCP(c),

Halina T. Kieraszewicz MD FrCP(C),

Bruce G. Dodgson MD FrcP(C), Jane L. Clement RN

\title{
Chemical regulation of ventilation during isoflurane sedation and anaesthesia in humans
}

To assess the effects of isofiurane on chemical regulation of ventilation, we studied the ventilatory responses to (1) hyperoxic hypercarbia, (2) isocapnic hypoxaemia, and (3) a single half vital capacity breath of carbon dioxide 20 per cent in oxygen in 12 human subjects, awake and sedated or anaesthetized with isoflurane, 0.1 or 1.1 MAC. Sedation did not alter ventilation nor the ventilatory response to hypercarbia but reduced the responses to hypoxaemia and to the half vital capacity breath of $\mathrm{CO}_{2}$. Anaesthesia reduced ventilation and the response to hypercarbia and nearly abolished the responses to hypoxaemia and to the breath of $\mathrm{CO}_{2}$. The results indicate that isofurane reduces venilatary responses to several chemical drives and that it selectively impairs those responses mediated by peripheral chemoreceptors. In these respects, isofurane is similar to halothane and enflurane.

\section{Key words}

ANAESTHETICS, VOLATILE: isoflurane; RECEPTORS: chemoreceptors; VENTILATION; carbon dioxide response, hypoxic response, regulation.

From the Department of Araesthesia, University Hospital and University of Western Ontario, London, Canada.

Supported by Medical Research Council (MRC) Grant \#6443 and a grant from Ohio Medical Anesthetics.

Address correspondence to: Dr. R.L. Knill, Department of Anaesthesia, University Hospital, P.O. Box 5339, Postal Stn. A., London, Canada N6A SA5.
General anaesthetic agents that depress ventilation have two fundamental effects on the chemical regulation of ventilation. First, they cause ventilation to be totally dependent upon chemical stimulation since reduction of stimuli below a critical threshold with passive hyperventilation results in apnoea. Second, they reduce ventilatory responses to added chemical stimuli.

Isoflurane, in anaesthetizing doses, depresses ventilation, ${ }^{1-3}$ renders ventilation dependent upon chemical stimuli ${ }^{2}$ and reduces the ventilatory response to added carbon dioxide. ${ }^{1}$ However, its cffect on xesponses to other chemical stimuli, in particular the response to hypoxaemia, is not known. Activity of the hypoxaemia response is of some interest, since halothane and enflurane impair it markedly, ${ }^{4,5}$ with important clinical implications. ${ }^{6}$

The purpose of this study was to examine the effects of a sedating and an anaesthetizing dose of isoflurane on the ventilatory responses to hyperoxic hypercarbia, isocapnic hypoxaemia and a single breath of carbon dioxide. The first of these responses is mediated primarily by central chemoreceptors, the remaining two by peripheral chemoreceptors.

\section{Methods}

The protocol for this study was approved by the Human Research Committee of the University of Western Ontario.

We studied 12 fit subjects while they were awake and while in a steady-state of either isoflurane sedation 0.1 MAC ( $\mathbf{n}=5$ ) or isoflurane anaesthesia 1.1 MAC $(\mathbf{n}=7)$ * Subjects who were sedated were either anaesthetists or anaesthetic residents.

*The isoflurane MAC value used was 1.28 per cent. 


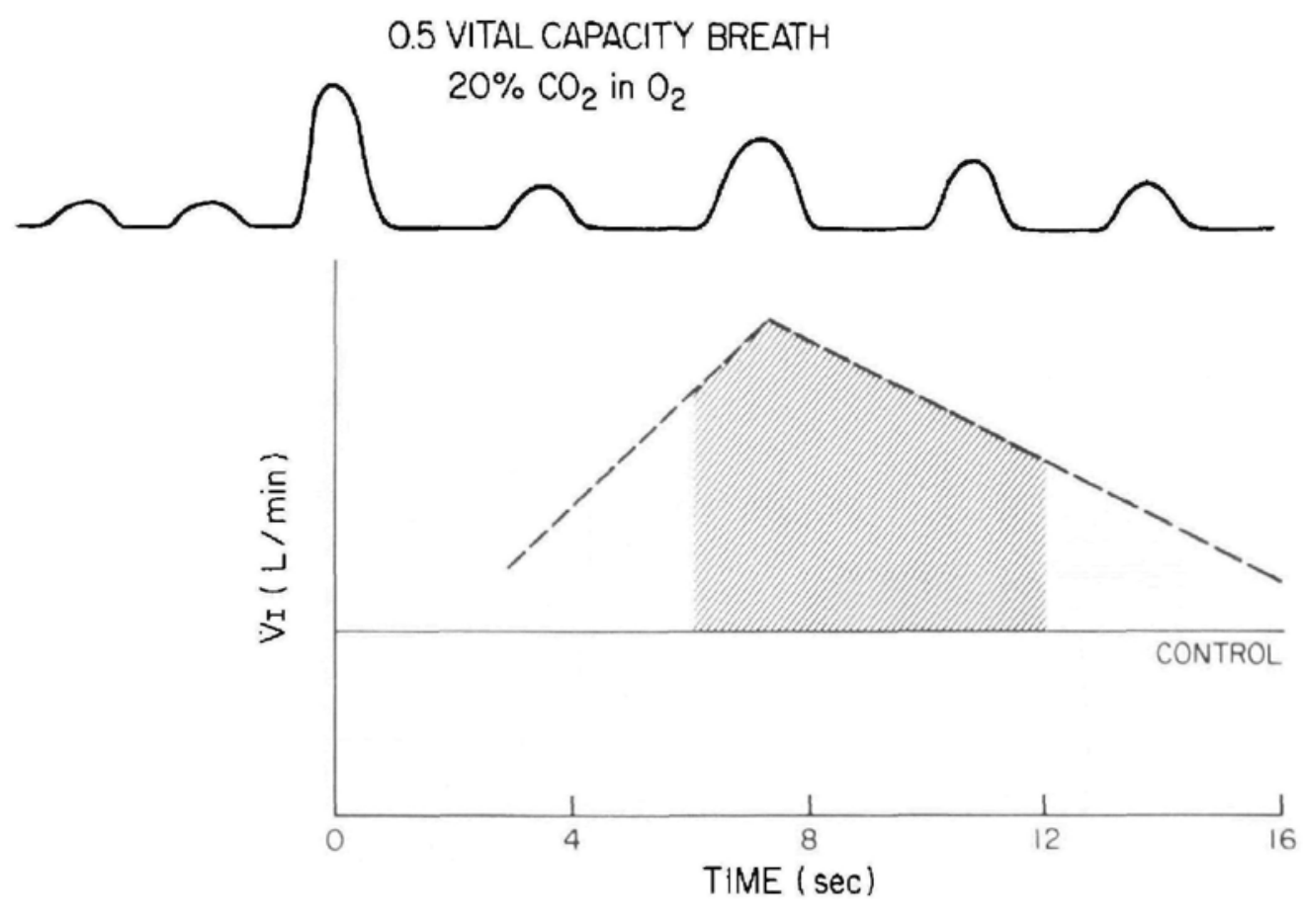

FIGURE 1 The single breath carbon dioxide test and its analysis. The upper trace is a typical spirogram record showing resting ventilation, the half vital capacity breath consisting of $\mathrm{CO}_{2} 20 \mathrm{per}$ cent in oxygen and the subsequent hyperpneic response. The broken linc of the graph is a diagrammatic representation of the response based upon a breath-by-breath delermination of instanlaneous ventilation. The " $\Delta \mathrm{V}^{\prime} \mathrm{CO}_{2}$ " was the average increment of inslantaneous ventilation above control in those breaths taken within 12 seconds of the breath of $\mathrm{CO}_{2}$, excluding the first (indicated by shaded area).

Subjects who were anaesthetized were patients who had agreed to an extra period of anaesthesia before undergoing an elective orthopaedic or dental surgical procedure. There were seven males and five females. Together, their ages, heights and weights were respectively $27 \pm 5$ years, $172 \pm 8 \mathrm{~cm}$ and 68 $\pm 12 \mathrm{~kg}$ (means \pm S.D.).

For the awake study, each subject relaxed in a comfortable chair in a darkened room and breathed through a mouthpiece with a nose-clip in place. He began by inhaling oxygen from a non-rebreathing system. When values of ventilation and end-tidal carbon dioxide concentration had been steady for five minutes, we recorded ventilation for a one minute period.

Next, the ventilatory response to each of the three chemical drives was tested. Individual tests were separated by at least five minutes. We induced hyperoxic hypercarbia progressively, using the Read rebreathing technique ${ }^{7}$ and allowing the equilibrated airway $\mathrm{CO}_{2}$ concentration to increase 2.0 per cent. We induced isocapnic hypoxaemia by the method of Weil, reducing end-tidal oxygen concentration to 6.0 per cent over 8-10 minutes. ${ }^{8}$

The response to a single breath of carbon dioxide was tested with a modification of the method of Sorensen et al. ${ }^{9}$ (Figure 1). The subject initially breathed quietly from a non-rebreathing system to establish his resting values of ventilation and end-tidal $\mathrm{CO}_{2}$ concentration. At the end of an expiration, he voluntarily and quickly inhaled a volume equivalent to half his measured vital capacity, the achievement of this volume being indicated by an audio signal activated by the pneumotachograph. He then exhaled to his end-expiratory position and relaxed. Circuits and valves were arranged 
so that the half vital capacity breath was 20 per cent carbon dioxide in oxygen and all other breaths were oxygen. The response was monitored for $30 \mathrm{sec}-$ onds. This test was repeated twice.

Isoflurane sedation was induced and maintained with sub-anaesthetic concentrations of isoflurane in oxygen while the subject sat comfortably in the same darkened room. After 25 minutes of inhalation and with end-tidal isoflurane steady at $0.1 \mathrm{MAC}$, we repeated ventilatory measurements and tests as in the awake state.

Each subject to be studied during anaesthesia was positioned supine. Anaesthesia was induced with isoflurane in oxygen. The glottis and upper trachea were sprayed with lidocaine four per cent and the trachea was intubated with an 8 or $9 \mathrm{~mm}$ cuffed orotracheal tube. Inspired isoflurane concentrations were set to achieve 1.1 MAC end-tidal, allowing 40 minutes to reach equilibrated and steady anaesthetic and respiratory states. The subject breathed spontaneously from a non-rebreathing system throughout. Five per cent dextrose in 0.2 per cent saline was infused as necessary to keep systolic arterial pressures at least 70 per cent of awake values.

When ventilation and end-tidal concentrations of isoflurane and carbon dioxide had been constant for ten minutes, we recorded a one minute period of ventilation. Duplicate samples of arterial blood were withdrawn anaerobically for determination of arterial isoflurane tension ${ }^{10}$ and arterial blood gas values. Ventilatory responses to chemical stimuli were then tested, using minor modifications of the procedures employed in studies of the awake and sedation states. ${ }^{4,5}$ During induction of hypoxaemia in anaesthetized subjects, we monitored arterial haemoglobin saturation continuously, using a HewlettPackard \#47201A ear oximeter, to prevent saturation from falling below 70 per cent. " To assess more precisely the relationship between end-tidal and arterial oxygen tensions during hypoxaemia, samples of arterial blood were withdrawn at intervals throughout hypoxaemia tests for subsequent blood gas analysis. The single half vital capacity breath of carbon dioxide was delivered from a collapsible bag under positive pressure.

During all tests in all states, exhaled gas was continuously sampled from a port close to the airway and analyzed for its carbon dioxide, oxygen and jsoflurane concentrations by a Perkin-Elmer \#1100 mass spectrometer, calibrated as in our previous studies. ${ }^{4.5}$ End-tidal concentrations were read from a time-based recording and were converted to tensions, using the measured barometric pressure of each testing day. Arterial isoflurane tension was determined using a multiple gas phase equilibration technique ${ }^{10}$ and a Hewlett-Packard \#5730 gas chromatograph. Arterial blood gas values were determined with a Radiometer Copenhagen BMS 3 System calibrated with Canadian Liquid Air Specialty Gases. The values of duplicate samples were averaged.

Inspired ventilation was measured with a pneumotachograph calibrated as previously described. ${ }^{4,5}$ Values of instantaneous ventilation, determined in the responses to hypercarbia and hypoxaemia, were based upon the averaged tidal volumes and respiratory cycle lengths of three consecutive breaths. Values of instantaneous ventilation, determined in the single breath $\mathrm{CO}_{2}$ responses, were based upon breath-by-breath calculations. All ventilatory volumes were expressed at body temperature and ambient pressure, saturated.

To depict the response to hyperoxic hypercarbia, we calculated the slope of the linear ventilation: $\mathrm{PET}_{\mathrm{CO}_{2}}$ relationship, using the method of least squares. The hypoxaemia response was represented by values of instantaneous ventilation found at $\mathrm{PET}_{\mathrm{O}_{2}}$ values of $53.2,13.3,9.3$ and $6.0 \mathrm{kPa}(400$, 100,70 and $45 \mathrm{mmHg}$ ) and also by the " $\Delta \dot{V}_{1_{45}}$," the measured increment of instantaneous ventilation between $\mathrm{PET}_{\mathrm{O}_{2}}$ values of $53.2 \mathrm{kPa}$ and $6.0 \mathrm{kPa}$. To depict the response to the single breath of carbon dioxide, we calculated the " $\Delta \mathrm{V}_{\mathrm{COO}_{2}}$ " (see Figure $\mathrm{l}$ ). Results of repeated single breath tests were averaged.

To check for possible differences between awake and sedation states, and between awake and anaesthesia states, we compared observations made in the same subjects using the two-tailed t-test for paired data. We considered a $p$ value of 0.05 or less as indicative of a significant difference.

\section{Results}

There were no important complications of these studies. Induction of anaesthesia with isoflurane was frequently accompanied by episodes of sneezing, coughing and/or breath-holding. However, these episodes were minor and short-lived. A steady-state of anaesthesia reduced systolic blood pressure modestly (average drop from awake to lowest stable anaesthetic value, $2.5 \mathrm{kPa}$ ) and in- 
TABLE

\begin{tabular}{|c|c|c|}
\hline & \multicolumn{2}{|c|}{ Isofiurane 0.1 MAC $(n=5)$} \\
\hline & Awake & Sedarion \\
\hline$\hat{V}_{1}\left(L \cdot \min ^{-1}\right)$ & $6.9 \pm 0.4$ & $6.5 \pm 0.4$ \\
\hline VT (L) & $0.62 \pm 0.04$ & $0.52 \pm 0.04$ \\
\hline f & $11 \pm 1$ & $13 \pm 2$ \\
\hline $\begin{aligned} \text { PET }_{\mathrm{CO}_{2}}(\mathrm{kPa}) & (\mathrm{mmHg})\end{aligned}$ & $\begin{array}{l}5.5 \pm 0.1 \\
(41 \pm 0.7)\end{array}$ & $\begin{array}{l}5.3 \pm 0.1 \\
(40 \pm 0.7)\end{array}$ \\
\hline \multirow{8}{*}{$\begin{array}{l}\text { Responses: } \\
\text { Hypercarbia, slope } \\
\left(\mathrm{L} \cdot \mathrm{min}^{-1} \cdot \mathrm{kPa}^{-1}\right) \\
\left(\mathrm{L} \cdot \mathrm{min}^{-1} \cdot \mathrm{mmHg}^{-1}\right) \\
\text { Hypoxaemia, } \Delta \dot{\mathrm{V}}_{\mathrm{L}_{45}} \\
\left(\mathrm{~L} \cdot \mathrm{min}^{-1}\right) \\
\text { Single brcath } \mathrm{CO}_{2}, \Delta \dot{\mathrm{V}}_{\mathrm{I}_{\mathrm{CO}}} \\
\left(\mathrm{L} \cdot \mathrm{min}^{-1}\right)\end{array}$} & & \\
\hline & $15.0 \pm 3.0$ & $19.5 \pm 6.0$ \\
\hline & $(2.0 \pm 0.4)$ & $(2.6 \pm 0.8)$ \\
\hline & & \\
\hline & $9.7 \pm 1.1$ & $4.1 \pm 1.1^{*}$ \\
\hline & $7.7 \pm 1.0$ & $5.6 \pm 0.8^{*}$ \\
\hline & \multicolumn{2}{|c|}{ Isofiurane $1.1 M A C(n=7)$} \\
\hline & Awake & Anaesthesia \\
\hline$\dot{V}\left(L \cdot \min ^{-1}\right)$ & $6.8 \pm 0.7$ & $4.9 \pm 0.4^{*}$ \\
\hline $\operatorname{Vr}(\mathrm{L})$ & $0.54 \pm 0.06$ & $0.17 \pm 0.01^{H}$ \\
\hline f & $13 \pm 1$ & $29 \pm 2^{*}$ \\
\hline $\mathrm{PET}_{\mathrm{CO}}(\mathrm{kPa})$ & $5.1 \perp 0.1$ & $5.9 \pm 0.4^{*}$ \\
\hline$(\mathrm{mmHg})$ & $(38 \pm 0.4)$ & $(44 \pm 2.8)$ \\
\hline $\begin{aligned} \mathrm{Paco}_{2} & \langle\mathrm{kPa}\rangle \\
& (\mathrm{mmHg})\end{aligned}$ & & $\begin{array}{l}6.5 \pm 0.4 \\
(49 \pm 2.7)\end{array}$ \\
\hline \multicolumn{3}{|l|}{ Responses: } \\
\hline \multicolumn{3}{|l|}{ Hypercarbia, slope } \\
\hline$\left(\mathrm{L} \cdot \min ^{-1} \cdot \mathbf{k P a}^{-1}\right)$ & $13.5 \pm 1.5$ & $4.5 \pm 0.7^{*}$ \\
\hline$\left(\mathrm{L} \cdot \min ^{-1} \cdot \mathrm{mmH}_{\mathrm{g}}{ }^{-1}\right)$ & $(1.8 \pm 0.2)$ & $(0.6 \pm 0.1)$ \\
\hline \multicolumn{3}{|l|}{ Hypoxaemia, $\Delta \dot{V}_{I_{45}}$} \\
\hline$\left(L \cdot \min ^{-1}\right)$ & $11.4 \pm 2.2$ & $0.3 \pm 0.3^{*}$ \\
\hline $\begin{array}{l}\text { Single breath } \mathrm{CO}_{2}, \Delta \dot{\mathrm{V}}_{\mathrm{C}_{2}} \\
\left(\mathrm{~L} \cdot \mathrm{min}^{-1}\right)\end{array}$ & $8.4 \pm 1.7$ & $1.2 \pm 0.5 * \dagger$ \\
\hline
\end{tabular}

All values mean \pm S.E.M.

* Significantly different from awake values $\mathrm{p}<0.05$.

$\dagger_{n}=5$.

creased heart rate slightly (average increase from awake to stable anaesthetic value, 6 beats $/ \mathrm{min}$ ). During anaesthesia, end-tidal and arterial tensions of isofurane were respectively $1.30 \pm 0.1$ and 1.26 $\pm 0.4 \mathrm{kPa}(9.8 \pm 0.1$ and $9.5 \pm 0.3 \mathrm{mmHg}$, means \pm S.E.M.).

Vencilatory findings are summarized in the Table and in Figures 2 and 3. Sedation did not detectably alter minute ventilation, tidal volume, breathing frequency nor values of $\mathrm{PET}_{\mathrm{CO}}$. Anaesthesia reduced minute ventilation and tidal volume, increased

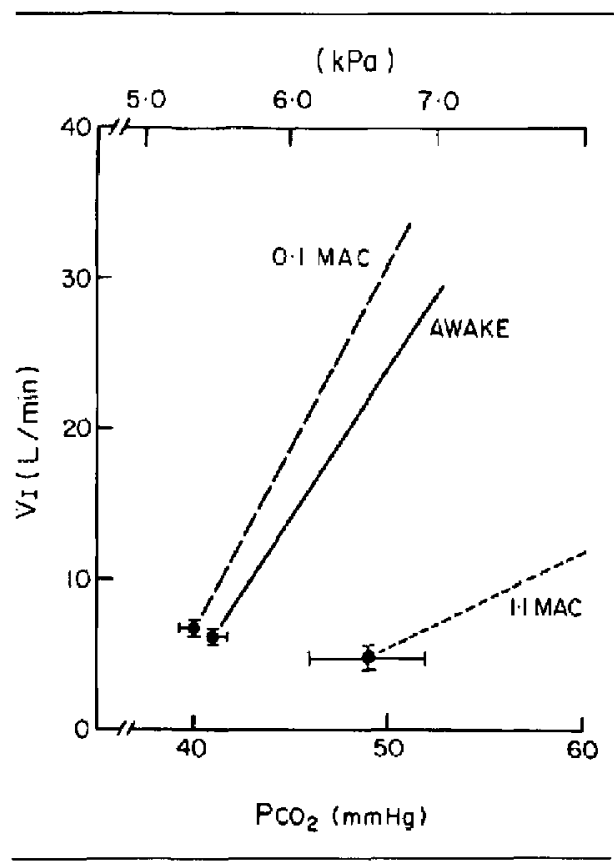

FIGURE 2 Ventilatory responses to hypercarbia of subjects sedated with isoflurane (0.1 MAC) and anaesthetized with isofurane (1.1 MAC). Dots represent mean values of ventilation at mean resting $\mathrm{PET}_{\mathrm{CO}_{2}}$ values of awake and sedated subjects and at mean resting $\mathrm{PaCO}_{2}$ values of anaesthetized subjects. Bars are \pm S.E.M. Lines extending from dots depict mean slopes of responses to hypercarbia. The awake response is that of the sedation group.

breathing frequency and elevated values of $P E T_{C O_{2}}$. During anaesthesia, there was a modest $P(E T-a){ }_{\mathrm{CO}_{2}}$ gradient.

Sedation did not detectably alter the ventilatory response to hyperoxic hypercarbia, but reduced the responses to hypoxaemia and to the single breath of $\mathrm{CO}_{2}$. Anaesthesia reduced the response to hyperoxic hypercarbia, virtually abolished the response to isocapnic hypoxaemia and markedly reduced the response to the single breath of $\mathrm{CO}_{2}$.

During anaesthesia and tests of the response to hypoxaemia, differences between end-tidal and arterial tensions of oxygen were as follows: at $\mathrm{PET}_{\mathrm{O}_{2}}$ values $13.0-13.6 \mathrm{kPa}(98-102 \mathrm{mmHg}), 1.4 \pm 0.2$ $\mathrm{kPa}(11=2 \mathrm{mmHg})$; at PET $_{\mathrm{O}_{2}}$ values 9.0-9.6 $\mathrm{kPa}$ $(68-72 \mathrm{mmHg}), 0.3 \pm 0.3 \mathrm{kPa}(2 \pm 2 \mathrm{mmHg}) ;$ and at $\mathrm{PET}_{\mathrm{O}_{2}}$ values $6.0-6.7 \mathrm{kPa}(45-50 \mathrm{mmHg}), 0.1 \pm$ $0.1 \mathrm{kPa}(1 \pm 1 \mathrm{mmHg}$ ) (means \pm S.E.M.). 


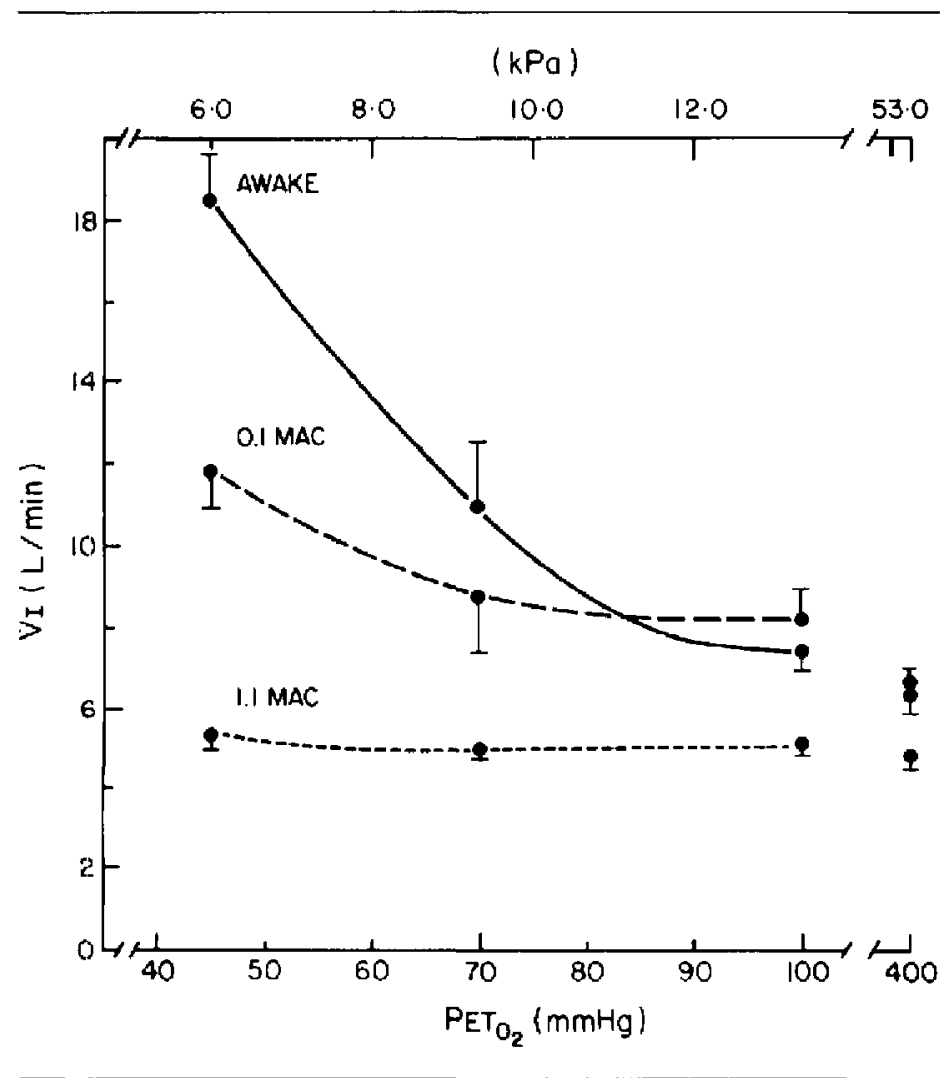

FIGURE 3 Ventilatory responses to isocapnic hypoxaemia of subjects sedated with isoflurane ( $0.1 \mathrm{MAC})$ and anaesthetized with isoflurane ( $1.1 \mathrm{MAC})$. Dots represent mean values of ventilation at $\mathrm{PET}_{2}$ values of $53.2,13.3,9.3$ and $6.0 \mathrm{kPa}(400,100,70$ and $45 \mathrm{mmHg}$ ). Bars are \pm S.E.M. Lines through dots were hand drawn. The awake respanse is that of the seduticin group.

\section{Discussion}

Experimental conditions were identical for studies of awake and sedation states, but there were several variables added during anaesthesia. These included the supine position, tracheal intubation, and, of potential relevance to testing responses to hypoxaemia, increased differences between end-tidal and arterial tensions of oxygen and elevated values of $\mathrm{PET}_{\mathrm{CO}_{2}}$. We doubt that any of these affected our results in an important way. The supine position does not alter ventilation and ventilatory responses to chemical stimuli in awake subjects. ${ }^{12,13}$ Tracheal intubation does not affect the response to hypercarbia in subjects lightly anaesthetized with halothane. ${ }^{4}$ Increased end-tidal to arterial oxygen ten- sion differences during anaesthesia might have decreased the validity of the end-tidal value as the measured stimulus of the response to hypoxaemia. However, at end-tidal tensions of $9.6 \mathrm{kPa}$ and less, where the ventilatory response to hypoxaemia is normally observed, these differences in anaesthetized subjects were small and quite similar to those found in awake subjects. ${ }^{8}$ An elevated carbon dioxide tension, as was present during anaesthesia, may have augmented the response to hypoxaemia. ${ }^{8}$ However, such an effect would have acted only to underestimate the magnitude of the depressive effect of isoflurane.

Isoflurane anaesthesia 1.1 MAC in our subjects reduced ventilation and tidal volume, increased 
breathing frequency and elevated values of $\mathrm{PET}_{\mathrm{CO}_{2}}$. The relative magnitudes of these effects were similar to those previously reported. ${ }^{1-3}$ Isoflurane sedation 0.1 MAC had no detectable effect on values of ventilation and $\mathrm{PET}_{\mathrm{CO}_{2}}$.

The ventilatory response to progressive or steadystate hyperoxic hypercarbia is effected by two sets of $\mathrm{CO}_{2}-\left[\mathrm{H}^{+}\right]$sensitive receptors, the central chemoreceptors located in the medulla and the peripheral chemoreceptors located in the carotid bodies of man. However, the contribution of the peripheral receptors is normally small $(<30$ per cent of total) $)^{14,15}$ and, accordingly, the response is considered to be primarily central chemoreceptor mediated. Isoflurane anaesthesia 1.1 MAC in our subjects reduced the response to progressive hyperoxic hypercarbia modestly, in keeping with previous observations. ' Isoflurane sedation 0.1 MAC had no detectable effect. In this respect, isoflurane is similar to several other anaesthetic agents. ${ }^{16}$

The increment of ventilation in response to isocapnic hypoxaemia is mediated exclusively by peripheral chemoreceptors. ${ }^{14.15}$ This response was selectively and markedly impaired by isoflurane. Sedation 0.1 MAC, which had no detectable effect on ventilation and the response to hyperoxic hypercarbia, reduced the hypoxaemia response to less than half of awake values. Anaesthesia 1.1 MAC virtually abolished it. Halothane and enflurane produce a similar disproportionate impairment of the response to hypoxaemia in human subjects. ${ }^{3,4}$ Interestingly, other anaesthetics, such as thiopentone and nitrous oxide, do not. ${ }^{16}$

The ventilatory response to a single large breath of carbon dioxide has been proposed as a test of the peripheral chemoreceptor mediated response to $\mathrm{CO}_{2}-\left[\mathrm{H}^{+}\right]$that excludes a central chemoreceptor mediated contribution. ${ }^{9,17}$ In this test, the subject voluntarily inhales a single large breath of $\mathrm{CO}_{2}$ and the result is an immediate, large and transient increment of $\mathrm{CO}_{2}$ in the blood. The added carbon dicxide is delivered sooner and much more rapidly to peripheral than to central chemoreceptors, due to different circulatory lag times and rates of local blood flow. Accordingly, the initial 11-15 seconds of the response can be considered to be mediated primarily, if not entirely, by peripheral chemoreceptors. ${ }^{917-19}$ As originally described, the test requires that the subject inhale a full vital capacity breath of carbon dioxide 15 per cent in oxygen. $9: 17$
Because a vital capacity breath cannot be delivered safely in anaesthetized subjects, we reduced the size of the breath to one half a vital capacity and increased its $\mathrm{CO}_{2}$ concentration to 20 per cent.*

The effect of isoflurane on the response to a single breath of $\mathrm{CO}_{2}$ was similar to its effect on the response to hypoxaemia. Sedation 0.1 MAC diminished it moderately; anaesthesia 1.1 MAC reduced it markedly. The results suggest that the depression of the single breath response may have been slightly less than the impairment of the response to hypoxaemia. However, this difference was not statistically significant. Whatever the relative magnitude of effect, isoflurane appears to be a potent depressant of both these physiological ventilatory reflexes mediated by peripheral chemoreceptors.

The results of the present study, together with other data, indicate that modern halogenated anaesthetics may be powerful depressants of several peripheral chemoreceptor mediated ventilatory reflexes in humans. Halothane, entlurane and isoflurane, in light anaesthetizing doses, virtually abolish the hyperpneic response to hypoxaemia. ${ }^{4,5,16} \mathrm{Halo}$ thane reduces the ventilatory response to hyperoxaemia and delays the response to a sudden $\mathrm{CO}_{2}$ stimulus generated by an intravenous bolus of sodium bicarbonate in a manner that suggests no contribution from peripheral chemoreceptors. ${ }^{19}$ Isoflurane greatly impairs the pcripheral chemoreceptor mediated response to a single breath of $\mathrm{CO}_{2}$. Halothane and enflurane severely reduce the response to a pharmacological stimulus of peripheral chemoreceptors - a small dose of doxapram. 4.5 Thus, in several respects, human subjects anaesthetized with halogenated agents behave almost as if lacking peripheral chemoreceptors. Although halothane is a direct and potent depressant of carotid body chemoreceptors in the cat, ${ }^{20}$ the site and mechanism of action of these agents on the peripheral chemoreflex pathway in humans remains unknown.

We conclude that with respect to chemical regulation of breathing, isoflurane is similar to halothane and enflurane. It reduces ventilatory

*Although these changes may have altered the magnitude of the stimulus and the response, they did not affect the essential nature and the validity of this test. This modification of the single breath test was used throughout this study. 
responses to several chenical stimuli, especially those responses mediated by peripheral chemoreceptors.

The most important clinical implications of these findings relate to the effect on the response to hypoxaemia. ${ }^{6}$ Abolition or marked depression of this reflex is a serious hazard to spontaneously breathing patients since it permits hypoxacmia to develop more readily, more quickly and to a more severe level than would otherwise be the case. Furthermore, loss of the hyperpneic response to hypoxaemia means loss of a useful clinical sign. These implications apply not only to patients anaesthetized with isoflurane, but also to patients recovering from isoflurane anaesthesia for as long as sedating doses of the agent persist.

\section{Acknowledgements}

The authors wish to thank the surgeons and operating room staff at University Hospital who cooperated in making the anaesthetic portion of the studies possible and Mrs. L. Nolan who helped prepare the manuscript.

\section{References}

1 Fourcade HE, Stevens WC, Larson Jr, CP et al. The ventilatory effects of Forane, a new inhaled anesthetic. Anesthesiology $1971 ; 35: 26-31$.

2 Hickey RF, Fourcade HE, Eger II EI et al. The effects of ether, halothane, and Forane on apneic thresholds in man. Anesthesiology 1971; 35: 32-7.

3 Eger II EI, Dolan WM, Stevens WC. Miller RD, Way WL. Surgical stimulation antagonizes the respiratory depression produced by Forane. Anesthesiology 1972; 36: 544-9.

4 Knill $R L$, Gelb $A W$. Ventilatory responses to hypoxia and hypercapnia during halothane sedation and anesthesia in man. Anesthesiology 1978; 49:244-51.

5 Knill RL, Manninen PH. Clement $J L$. Ventilation and chemoreflexes during enflurane sedation and anaesthesia in man. Can Anaesth Soc J 1979; 26: 353-60.

6 Knill RL, Gelb AW. Peripheral chemoreceptors during anesthesia: Are the watchdogs sleeping? Anesthesiology 1982; 57: 151-2.

7 Read DJC. A clinical method for assessing the ventilatory response to carbon dioxide. Australas Ann Med 1967; 16: 20-32.
8 Weil JV. Byrne-Quinn E, Sodal IE et al. Hypoxic ventilatory drive in normal man. J Clin Invest 1970; 49: $1061-72$.

9 Sorensen $S C, C r u z J C$. Ventilatory response to a single breath of $\mathrm{CO}_{2}$ in $\mathrm{O}_{2}$ in normal man at sea level and high altitude. J Appl Physiol 1969; 27: 186-90.

10 Knill RL, Lok PYK, Sirupat JP, Lam AM. Blood solubility of isoflurane measured by a multiplc gas phase equilibration technique. Can Anaesth Soc J 1983; 30: 155-61.

11 Knill RL, Clement JL, Kieraszewicz HT, Dodgson $B G$. Assessment of two non-invasive monitors of arterial oxygenation in anesthetized man. Anesth Analg 1982; 61: 582-6.

12 Rigg IRA, Rebuck AS. Campbell EJM. The effect of posture on the ventilatory response to $\mathrm{CO}_{2}, \mathrm{~J}$ Appl Physiol 1974; 37: 487-90.

13 Slutsky AS, Goldstein RG. Rebuck AS. The effect of posture on the ventilatory response to hypoxia. Can Anaesth Soc J 1980; 27: 445-8.

14 Wade JG, Larson $C P$, Hickey $R F$, Ehrenfeld $W K$. Severinghaus $J W$. Effect of carotid endarterectomy on carotid chemoreceptor and baroreceptor function in man. N Engl J Med 1970; 282: 823-9.

15 Lugliani $R$, Whipp BJ, Seard C, Wasserman K. Effect of bilateral carotid-body resection on ventilatory control at rest and during exercise in man. N Engl J Med 1971; 285: 1105-11.

16 Knill $R L$, Clement $J L$. Variable effects of anacsthetics on the ventilatory response to hypoxaemia in man. Can Anaesth Soc J 1982; 29: 93-9.

17 Gabel RA, Kronenberg RS, Severinghaus $J W$. Vital capacity breaths of $5 \%$ or $15 \% \mathrm{CO}_{2}$ in $\mathrm{N}_{2}$ or $\mathrm{O}_{2}$ to test caratid chemosensitivity. Resp Physiol 1973; 17: 195-208.

18 Gelfand R, Lambertsen CJ. Dynamic respiratory response to abrupt change of inspired $\mathrm{CO}_{2}$ at normal and high $\mathrm{PO}_{2}$. J Appl Physiol 1973; 35: 903-13.

19 Duffin J, Triscolt A, Whitman JG. The effect of halothane and thiopentone on ventilatory responses mediated by the peripheral chemoreceptors in man Br J Anaesth 1976; 48: 975-80.

20 Davies $R O, E d w a r d s M W$, Lahiri S. Halothane depresses the response of carotid body chemoreceptors to hypoxia and hypercapnia in the cat. Anesthesiology 1982; 57: 153-9. 
Résumé

Afin d'étudier les effets de l'isoflurane sur la régulation chimique de la ventilation nous avons étudiè la réponse ventilatoire d: I) I' hypercarbie hyperoxique; 2) I' hypoxémie isocapnique; 3) l'inspiration d' un mélange gazeıx contenant 20 pour cent de $\mathrm{CO}_{2}$ dans loxygène. La quantité de ce mélange inhalé était équivalente à la moitié de la capacité vitale inspirée en une seule fois.

Ce travail a été effectué chez 12 volontaires d' abord éveillês, ensuite sous sédation et enfin anesthésiés à l'isofurane a 0.1 et 1.1 MAC.

La sédation à l'isoflurane n'a pas modifié la ventilation, non plus que la réponse ventilatoire al hypercarbie mais a réduit la réponse à l'hypoxémie et à l' inspiration de haute concentration de $\mathrm{CO}_{2}$, Pour sa part, l'amesthésie a réduit la ventilation et la réponse à l'hypercarbie et, à toutes fins utiles, a aboli la réponse à l'hypoxémie et à l'inspiration de $\mathrm{CO}_{2}$. Ce résultat indique que l'isofurane diminue la réponse ventilatoire à plusieurs des stimulants chimiques et qu' il prêvient de façon sélective les réponses qui s'effectuent par les chémorécepteurs périphériques. En ceci, l'isoflurane est semblable à lhalorhane et à lenflurance. 